\title{
ASMA BRÔNQUICA: O PRESENTE E O FUTURO
}

\author{
BRONCHIAL ASTHMA: TODAY AND TOMORROW
}

Elcio O. Vianna

Médico Colaborador da Divisão de Pneumologia do Departamento de Clínica Médica da Faculdade de Medicina de Ribeirão Preto da Universidade de São Paulo.

Correspondência: Dr. Elcio O. Vianna - R. Margarita C. A. Proença, 200 - São Paulo - SP - CEP: 05587-140; Fax: 011-8131752; E-mail: evianna@uol.com.br

VIANNA EO. Asma brônquica: o presente e o futuro. Medicina, Ribeirão Preto, 31: 229-240, abr./jun. 1998.

RESUMO: A asma é caracterizada por obstrução reversível, inflamação e hiperreatividade brônquicas. O diagnóstico é baseado em informações clínicas e testes de função pulmonar. Os eosinófilos são uma característica importante da fisiopatologia da asma. Eles produzem fatores quimiotáxicos, broncoconstrictores e vasoativos, que conduzem à hiperreatividade brônquica. Além disso, os eosinófilos danificam o tecido circunvizinho, através da liberação do conteúdo protéico de seus grânulos.

As recomendações para o tratamento da asma são baseadas em quatro componentes: uso de medidas objetivas da função pulmonar para avaliar a gravidade da asma e monitorar o curso da terapia; controle ambiental para evitar ou eliminar fatores precipitantes de sintomas ou crises; terapia farmacológica a longo prazo, para tratar e prevenir inflamação de via aérea e, também, para tratar as agudizações; e educação do paciente, criando uma parceria entre o paciente, a família e o clínico.

Os $\beta_{2}$-agonistas são a classe de drogas mais comumente usadas para o tratamento da asma. Usar essas drogas em demanda é freqüentemente mais aceito e recomendado. Em asma aguda, um $\beta_{2}$-agonista é ainda o medicamento de escolha. Agonistas de ação prolongada, salmeterol e formoterol, podem diminuir sintomas de asma durante o dia e à noite. A teofilina, cujo uso esteve limitado pela toxicidade, pode recuperar uma posição importante no tratamento da asma, com a descoberta de suas ações antiinflamatórias. O brometo de ipratrópio, uma droga anticolinérgica, ainda espera um papel definido no tratamento da asma. Os corticoesteróides inalatórios têm efeitos mensuráveis nos sintomas, função pulmonar, reatividade brônquica e inflamação. Os efeitos colaterais limitam a administração sistêmica, mas não a administração tópica. Preparações mais novas, como budesonida, flunisolida e fluticasona diminuem a incidência de possíveis efeitos colaterais, porque têm uma melhor relação efeito tópico/efeito sistêmico.

Medicamentos recentemente lançados incluem os antileucotrienos (anti-LTs), agentes que funcionam bloqueando a interação dos LTs com seus receptores (antagonistas de receptor) ou inibindo a síntese de LTs (inibidores de síntese). Representantes dos antagonistas são zafirlukast, pranlukast e montelukast. Pranlukast, o primeiro antagonista de receptor a ser comercializado, melhora função pulmonar e sintomas, dependendo da dose. Zileuton, um inibidor de síntese, demostrou melhorar a função pulmonar, reduzir sintomas, reduzir uso de $\beta$-agonistas e crises de asma. Esses efeitos positivos são dose-dependentes e anormalidades da função hepática parecem ser um limite relevante ao uso de zileuton, em alguns pacientes.

UNITERMOS: Asma. Broncodilatadores.

\section{INTRODUÇÃO}

A incidência, a mortalidade e o número de hospitalizações por asma continuaram aumentando na última década. Essas mudanças renovaram o interesse na pesquisa da fisiopatologia e do tratamento dessa morbidade. Muitos estudos clínicos e experimentais evidenciaram o papel da inflamação na fisiopatologia 
e, como resultado, ressaltaram a importância do tratamento antiinflamatório em detrimento do broncodilatador. Iniciativas em todo o mundo, dirigidas à pesquisa, continuam nos ajudando a entender melhor as causas da doença e oferecendo novas modalidades de tratamento. Muitos países e associações internacionais têm programas especiais, reunindo um significativo número de centros e pesquisadores, o que está proporcionando um ritmo acelerado na busca da cura da asma. Dos consensos às novas formas de tratamento, a maior parte das recentes descobertas é resultado de tal integração científica.

Dentre esses avanços, estão os antagonistas de receptores dos leucotrienos, inibidores da enzima 5-lipoxigenase e inibidores seletivos de fosfodiesterases. Cada uma dessas classes de drogas ainda necessita mais estudos clínicos e epidemiológicos, antes de definirmos seus papéis na terapia da asma. Novos mediadores são e serão focos de atenção no desenvolvimento de medicamentos. Por exemplo, bloquear a IgE ou as interleucinas, etapas do processo inflamatório da asma, pode ser uma futura solução para interferir na fisiopatologia da doença. O potencial do tratamento genético também poderá influenciar o tratamento da asma nas próximas décadas.

Embora os consensos e suas resultantes diretrizes ("guidelines") não sejam inovações terapêuticas, é importante entender e seguir essas recomendações para melhorar o uso de drogas antigas e modernas. As diretrizes, elaboradas por sociedades científicas, órgãos de saúde e governos são cada vez mais freqüentes. A proposta dos organizadores é resumir a literatura médica, chegar a um consenso sobre condutas e influenciar a prática clínica. As primeiras diretrizes foram publicadas no começo dos anos 90 e já foram atualizadas em novas edições ${ }^{(1)}$. Poucos estudos têm pesquisado o impacto desses consensos na prática cotidiana e, no caso da asma, esses estudos ainda são necessários. Um progresso considerável aconteceu em relação ao conhecimento que os médicos têm sobre o componente inflamatório da asma. Tal progresso foi dectado pelo aumento do número de prescrições de drogas que atuam nesse componente da doença.

\section{DEFINIÇÕES}

A asma brônquica é caracterizada por obstrução de via aérea reversível, inflamação das vias aéreas e hiperreatividade brônquica. Em alguns pacientes, a reversibilidade não é completa, ou seja, a função pulmonar não retorna a valores normais. As medidas de volume expiratório do primeiro segundo (VEF1) são freqüentemente realizadas antes e depois do uso de broncodilatadores para se confirmar a reversibilidade da obstrução. Em raras situações, entretanto, a reversibilidade não é detectada através da espirometria, sendo, então, necessárias as medidas de volumes pulmonares estáticos, como volume residual, capacidade residual funcional e capacidade pulmonar total ou índices ainda mais sensíveis como: resistência das vias aéreas, condutância e condutância específica.

Do ponto de vista prático, o diagnóstico de asma deve se basear em dados obtidos pela história, exame físico, radiografia e testes de função pulmonar. A presença de hiperreatividade das vias aéreas pode auxiliar o diagnóstico em diversas situações, apesar de não ser específica para asma. A hiperreatividade brônquica pode ser definida como uma resposta exagerada a estímulos broncoconstrictores que não causariam broncoespasmo em indivíduos normais. A hiperreatividade brônquica pode ser medida por testes de broncoprovocação (histamina, metacolina, exercício, etc) ou inferida pela variabilidade circadiana da função pulmonar. Nesse caso, a intensidade da piora da asma entre o dia e a noite se correlaciona com o grau de hiperreatividade das vias aéreas.

\section{FISIOPATOLOGIA}

Clinicamente, é possível dividir a asma em atópica e não atópica. A asma atópica, ou extrínseca, caracteriza-se por ocorrer em indivíduos com história familiar da doença, comumente associada a eczema e/ou rinite alérgica. As crises são desencadeadas por alérgenos ambientais. Os testes de hipersensibilidade mediada por IgE são positivos. A dessensibilização pode, ocasionalmente, ser bem sucedida. A asma brônquica não atópica, ou intrínseca, caracteriza-se por apresentar etiologia complexa, sem relação com alérgenos ou $\operatorname{IgE}$, sendo incomum a ocorrência de eczema ou rinite. A eosinofilia em sangue periférico e em escarro freqüentemente acompanha ambos os tipos de asma, atópica e não atópica.

Independentemente do estímulo causador, os eosinófilos migram para as vias aéreas e podem levar à hiperreatividade brônquica através da liberação de mediadores broncoconstrictores, quimiotáxicos e vasoativos. Os eosinófilos também liberam substâncias granulares citotóxicas que lesam tecidos das vias aéreas, principalmente o epitélio. As principais proteínas 
catiônicas que constituem os grânulos eosinofílicos são: a proteína básica principal, a proteína catiônica eosinofílica (ECP), a neurotoxina derivada do eosinófilo, a peroxidase eosinofílica e a proteína $\mathrm{X}$ do eosinófilo. Inclusive, a concentração de ECP sérica pode ser um poderoso indicador da gravidade da asma e da eficácia do tratamento ${ }^{(2)}$. Do ponto de vista anatomopatológico, a presença do eosinófilo também é marcante, tendo a asma recebido a designação "bronquite crônica descamativa eosinofílica", ao se descreverem os achados de pacientes que morreram em crise de asma. Esses achados eram: infiltrado celular, predominantemente eosinofílico, descamação epitelial, secreção na via aérea, hipertrofia de musculatura lisa, broncoespasmo e edema.

Várias outras células inflamatórias são corresponsáveis pelos fenômemos associados à fisiopatologia da asma. Os mastócitos, envolvidos diretamente nos processos alérgicos, são encontrados em quantidade aumentada no lavado broncoalveolar de asmáticos. Acredita-se que os mediadores mastocitários determinam um broncoespasmo imediato (reação asmática imediata) e causam migração de outras células inflamatórias (reação asmática tardia). Os linfócitos exercem um papel regulador, participando da inflamação brônquica pela liberação de interleucinas que controlam a atividade dos basófilos, mastócitos e eosinófilos (Figura 1). Além disso, os linfócitos reco-

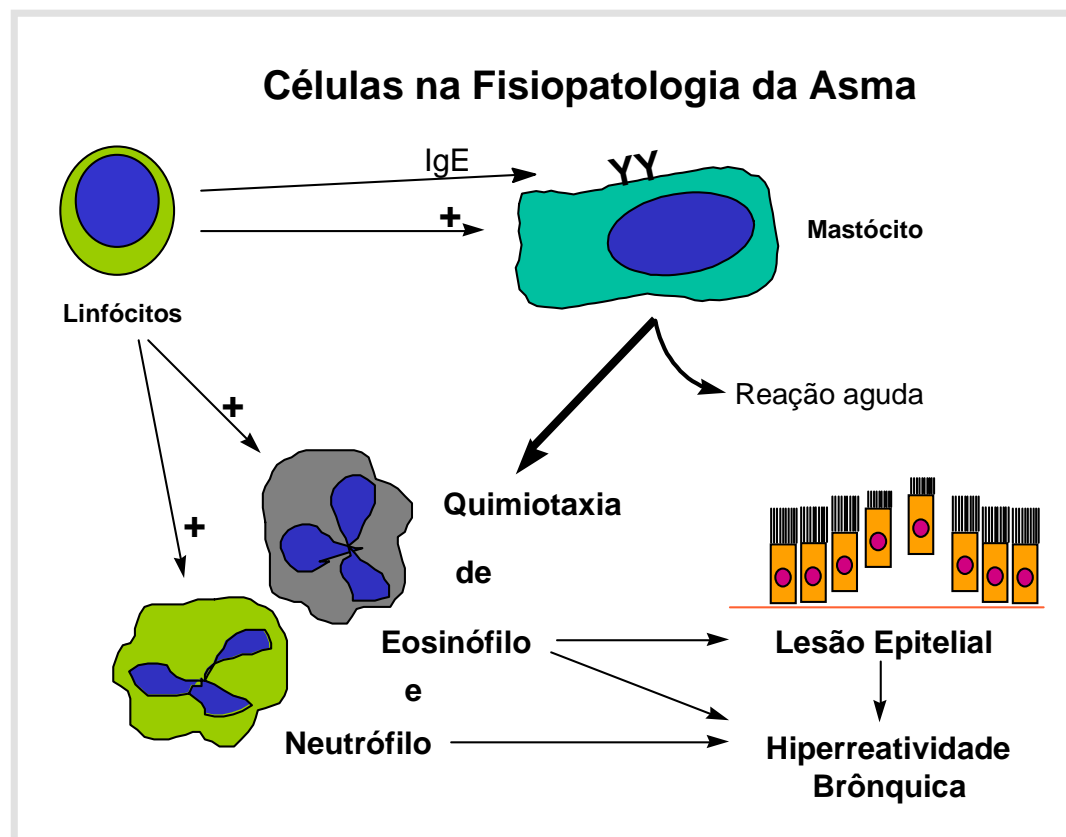

Figura 1 - Células envolvidas na fisiopatologia da asma. nhecem e respondem aos alérgenos através de aumento na produção de IgE. Os neutrófilos, cujo papel na asma humana não está confirmado, participam ativamente da gênese da asma, em alguns modelos animais ${ }^{(3)}$.

Analisando os mediadores, envolvidos na fisiopatologia da asma, temos um número progressivamente maior de substâncias que podem representar futuras opções de intervenção terapêutica. As Tabelas I e II listam os mediadores mais estudados e mais relacionados à asma. Desde a descoberta de um novo mediador até a confirmação de sua relevância para asma, muitas etapas da pesquisa são encaminhadas, visando, um dia, a utilização deste mediador como via de tratamento. Inicialmente, os mediadores são encontrados em associação com a asma experimental e, depois, humana; essa associação pode ser a presença ou capacidade do mediador em induzir a doença ou partes dela. Em etapas seguintes, modos de inibir esses mediadores são testados, em animais e humanos, para que a relevância do mediador seja corroborada. As tabelas I e II apresentam informações categorizadas para vários componentes da fisiopatologia da asma.

\section{TRATAMENTO NÃO FARMACOLÓGICO}

Para o tratamento a longo prazo, é essencial identificar e reduzir a exposição a alérgenos, a irritantes e controlar outros fatores capazes de aumentar os sintomas ou precipitar crise de asma. Os fatores são: alérgenos inalatórios, exposições ocupacionais e desencadeantes não alérgicos. Os alérgenos mais importantes por via inalatória são antígenos animais, poeira doméstica, baratas, bolor e fungos. Medidas para reduzi-los são: remoção de carpetes, redução da umidade domiciliar para menos de $50 \%$ e extermínio das baratas. Para exposições ocupacionais, também é necessário identificar o agente e interromper o contato. Fatores não alérgicos são irritantes, como fumo e poluição (de dentro e de fora de casa), condições ou drogas que podem piorar a asma: rinite, sinusite, refluxo gastroesofágico, infecções por vírus, betabloqueadores, sensibilidade a sulfitos, a aspirina ou a outros antiinflamatórios não hormonais. 
Tabela I - Mediadores da asma brônquica

\begin{tabular}{lcccccc}
\hline & $\begin{array}{c}\text { Presença na } \\
\text { asma (animal) }\end{array}$ & $\begin{array}{c}\text { Presença na } \\
\text { asma (humana) }\end{array}$ & $\begin{array}{c}\text { Indução de } \\
\text { asma (animal) }\end{array}$ & $\begin{array}{c}\text { Indução de } \\
\text { asma (humana) }\end{array}$ & $\begin{array}{c}\text { Bloqueio da } \\
\text { asma (animal) }\end{array}$ & $\begin{array}{c}\text { Bloqueio da } \\
\text { asma (humana) }\end{array}$ \\
\hline Histamina & $\operatorname{sim}$ & $\operatorname{sim}$ & $\operatorname{sim}$ & $\operatorname{sim}$ & NÃO & NÃO \\
PAF & $\operatorname{sim}$ & $\operatorname{sim}$ & $\operatorname{sim}$ & $\operatorname{sim}$ & $\operatorname{sim}$ & NÃO \\
Leucotrienos & $\operatorname{sim}$ & $\operatorname{sim}$ & $\operatorname{sim}$ & $\operatorname{sim}$ & $\operatorname{sim}$ & $\operatorname{sim}$ \\
IgE & $\operatorname{sim}$ & $\operatorname{sim}$ & $\operatorname{sim}$ & $\operatorname{sim}$ & $\operatorname{sim}$ & $\operatorname{sim}$ \\
Substância P, & & & & $\operatorname{sim}$ & $\operatorname{sim}$ & em testes \\
NKA, VIP & $\operatorname{sim}$ & $+/-$ & $\operatorname{sim}$ & $\operatorname{sim}$ & NÃO & NÃO \\
Prostaglandinas & $\operatorname{sim}$ & $\operatorname{sim}$ & $\operatorname{sim}$ & $\operatorname{sim}$ & em testes & em testes \\
Bradicinina & $\operatorname{sim}$ & $\operatorname{sim}$ & $\operatorname{sim}$ & $\operatorname{sim}$ & $\operatorname{sim}$ & - \\
Endotelina & $\operatorname{sim}$ & $\operatorname{sim}$ & $\operatorname{sim}$ & - & sim & - \\
Moléculas de & & $\operatorname{sim}$ & - & &
\end{tabular}

PAF: Fator agregador plaquetário; NKA: Neurocinina A; VIP: Peptídeo vasoativo intestinal;

+/- dados controversos; - sem dados

Tabela II - Citocinas na asma brônquica

\begin{tabular}{lcccccc}
\hline & $\begin{array}{c}\text { Presença na } \\
\text { asma (animal) }\end{array}$ & $\begin{array}{c}\text { Presença na } \\
\text { asma (humana) }\end{array}$ & $\begin{array}{c}\text { Indução de } \\
\text { asma (animal) }\end{array}$ & $\begin{array}{c}\text { Indução de } \\
\text { asma (humana) }\end{array}$ & $\begin{array}{c}\text { Bloqueio da } \\
\text { asma (animal) }\end{array}$ & $\begin{array}{c}\text { Bloqueio da } \\
\text { asma (humana) }\end{array}$ \\
\hline IL-5 & $\operatorname{sim}$ & $\operatorname{sim}$ & $\operatorname{sim}$ & $\operatorname{sim}$ & $\operatorname{sim}$ & - \\
IL-4 & $\operatorname{sim}$ & $+/-$ & $\operatorname{sim}$ & $\operatorname{sim}$ & $\operatorname{sim}$ & sim \\
TNF & $\operatorname{sim}$ & $\operatorname{sim}$ & $\operatorname{sim}$ & $\operatorname{sim}$ & $\operatorname{sim}$ & - \\
IL-1 & $\operatorname{sim}$ & $\operatorname{sim}$ & $\operatorname{sim}$ & - & $\operatorname{sim}$ & em teste \\
IL-3 & $\operatorname{sim}$ & NãO & $\operatorname{sim}$ & - & $\operatorname{sim}$ & - \\
Interferon- $\gamma$ & $\operatorname{sim}$ & $\operatorname{sim}$ & $\operatorname{sim}$ & $\operatorname{sim}$ & $\operatorname{sim}$ & - \\
GMCSF & $\operatorname{sim}$ & $\operatorname{sim}$ & $\operatorname{sim}$ & $\operatorname{sim}$ & - & - \\
IL-8 & - & $\operatorname{sim}$ & $\operatorname{sim}$ & $\operatorname{sim}$ & - & - \\
IL-6 & $\operatorname{sim}$ & $\operatorname{sim}$ & $\operatorname{sim}$ & $\operatorname{sim}$ & - & - \\
\hline
\end{tabular}

IL: interleucina; TNF: fator de necrose tumoral; GMCSF: fator estimulante de colônia granulomonocitária;

+/- dados controversos; - sem dados.

Atualmente se preconiza que o paciente e sua família assumam conjuntamente o tratamento farmacológico, as estratégias de controle ambiental, a identificação e auto-tratamento das exacerbações e a comunicação apropriada com o sistema de saúde. A educação em asma é o mecanismo pelo qual os pacientes aprendem a realizar essas tarefas. A educação deve começar no momento em que a asma é diagnosticada e deve estar integrada a todas as etapas do tratamento da asma. As instituições responsáveis por saúde precisam sistematicamente ensinar e rever com os paci- entes como cuidar da asma. Os pacientes devem também receber e aprender a usar um diário escrito com um plano de detecção e de ação para as exacerbações. É especialmente importante fornecer o plano, por escrito, para pacientes com asma persistente, moderada e grave, ou história de crises graves. A aderência deve ser estimulada através da comunicação livre e aberta, individualizando, revendo e ajustando os planos na medida do necessário; enfatizando os objetivos e os resultados obtidos e incentivando a participação da família. 


\section{DISFUNÇÃO DAS CORDAS VOCAIS}

A disfunção das cordas vocais (DCV) é uma causa de obstrução das vias aéreas que pode mimetizar a asma. Um perfil comum, mas não obrigatório, de pacientes com essa síndrome é mulher, entre vinte (20) e quarenta (40) anos, com educação de nível superior, trabalhadora do sistema de saúde e acima do peso ideal. Geralmente, os pacientes são erroneamente diagnosticados como asmáticos, não responsivos a tratamento, usam grande quantidade de medicamentos, têm história de internações hospitalares, visitas a prontosocorro e entubação orotraqueal. Em alguns pacientes, o exercício físico pode desencadear a obstrução. A laringe é apontada como a área da obstrução que não melhora com broncodilatadores, mas melhora com inalação da mistura de hélio e oxigênio (70\% e 30\%, respectivamente). $\mathrm{O}$ diagnóstico definitivo se dá pela observação das cordas vocais que apresentam um movimento paradoxal de adução durante a inspiração.

\section{TRATAMENTO FARMACOLÓGICO}

\subsection{Broncodilatores - agonistas $\boldsymbol{\beta}_{2}$-adrenérgicos}

Os agonistas $\beta_{2}$ estimulam receptores do tipo $\beta_{2}$-adrenérgico da membrana celular, resultando em aumento do AMPc (monofosfato de adenosina cíclico) intracelular, que causa relaxamento da musculatura lisa, aumento da frequiência do batimento ciliar e redução da viscosidade do muco. Os agonistas $\beta_{2}$-adrenérgicos, de ação prolongada, cujo efeito broncodilatador dura doze (12) horas, possuem características lipofílicas e alta afinidade pelos receptores. Com isso, formoterol e salmeterol, agentes de ação prolongada, ligam-se por mais tempo aos receptores. A seletividade $\beta_{2}$ e a ação prolongada representam um grande avanço no tratamento da asma, por exemplo, para pacientes com asma noturna. Entretanto, alguns problemas ainda existem e limitam os benefícios desses medicamentos. Por causa da presença dos receptores $\beta_{2}$ em muitos tecidos, efeitos indesejáveis ocorrem pela absorção sistêmica destes agonistas. A prevenção de tais efeitos pela redução da concentração plasmática da droga é uma das vantagens da administração dos $\beta$-agonistas por via inalatória.

A Tabela III mostra os efeitos colaterais dos $\beta$-agonistas. A maioria deles desaparece com a continuidade do tratamento e não tem implicações a longo prazo. Os efeitos cardíacos também não representam risco aumentado, conforme demonstrado em estudos multicêntricos ${ }^{(4)}$. Além da toxicidade por absorção sistêmica, outros problemas potenciais devem ser mencionados, como tolerância ao efeito broncodilatador, tolerância ao efeito broncoprotetor, aumento da reatividade das vias aéreas e aumento da mortalidade.

\begin{tabular}{|c|c|}
\hline Efeitos colaterais & Mecanismos \\
\hline Tremor & $\begin{array}{l}\text { Estímulo do receptor } \beta_{2} \text {-adre- } \\
\text { nérgico no músculo esque- } \\
\text { lético }\end{array}$ \\
\hline Taquicardia e arritmias & $\begin{array}{l}\text { Vasodilatação com taquicardia } \\
\text { reflexa e estímulo do receptor } \\
\beta_{2} \text {-adrenérgico no coração }\end{array}$ \\
\hline Queda da $\mathrm{PO}_{2}$ & $\begin{array}{l}\text { Vasodilatação em áreas de va- } \\
\text { soconstricção pulmonar com- } \\
\text { pensatória, piorando o desequi- } \\
\text { líbrio ventilação-perfusão }\end{array}$ \\
\hline $\begin{array}{l}\text { Hiperglicemia, Hipopo- } \\
\text { tassemia }\end{array}$ & $\begin{array}{l}\text { Glicólise e liberação de insuli- } \\
\text { na com passagem do potássio } \\
\text { para o meio intracelular }\end{array}$ \\
\hline
\end{tabular}

$\mathrm{O}$ uso de agonistas $\beta_{2}$-adrenérgicos conforme a demanda, ou seja, quando necessário para o alívio imediato dos sintomas, é aceito e freqüentemente recomendado. Entretanto, ainda é motivo de debate. Um estudo recente mostrou que, em pacientes com asma leve, o uso regular de salbutamol não se associa a efeitos deletérios para o controle da asma. Por outro lado, os autores não demonstraram que o uso rotineiro (de horário) traz mais benefícios. O estudo concluiu que, em pacientes com asma leve, o uso conforme a demanda deve ser empregado e ajuda a diminuir o custo da medicação ${ }^{(5)}$.

Os $\beta$-agonistas são medicamentos de primeira escolha no tratamento da asma induzida por exercício. A inalação desses agentes previne o desenvolvimento de broncoespasmo durante ou após o esforço físico. Os $\beta$-agonistas de ação prolongada podem ser administrados duas vezes ao dia para a prevenção de sintomas. São particularmente eficazes para pacientes que acordam durante a noite, com sintomas de asma. A melhora dos sintomas noturnos, obtida com 
salmeterol e formoterol, não se associa a mudanças da inflamação de vias aéreas, descartando, nesse caso, um papel antiinflamatório relevante desses agonistas.

$\mathrm{Na}$ asma aguda, os $\beta$-agonistas são drogas de primeira escolha. Geralmente, o início do tratamento consiste de inalações de agonistas de curta duração (salbutamol, fenoterol ou terbutalina) até três vezes na primeira hora e, depois, uma vez por hora. Tal tratamento pode ser dado continuamente até que uma resposta clínica adequada seja obtida ou efeitos colaterais limitem a continuação (p. ex.: taquicardia, arritmias ou tremores). Os agonistas de ação prolongada não devem ser usados no tratamento da crise asmática.

\subsection{Broncodilatadores - Teofilina}

Os mecanismos de ação da teofilina, ainda indeterminados, podem se dever ao aumento de AMPc no músculo liso brônquico e à inibição de fosfodiesterases. Provavelmente, a inibição de isoenzimas da fosfodiesterase tem efeitos benéficos que vão além da broncodilatação, como efeitos antiinflamatórios e imunomoduladores. A teofilina e outras xantinas têm um potencial tóxico maior do que o de qualquer outra medicação para asma. A toxicidade é dose dependente e o risco aumenta quando a concentração sérica ultrapassa $20 \mu \mathrm{g} / \mathrm{ml}$. Isso torna o uso de teofilina mais complicado, exigindo dosagens séricas e atenção especial para os fatores que interferem nos níveis séricos da droga. Tudo isso e a ênfase na abordagem antiinflamatória colocaram a teofilina como droga de terceira linha, no tratamento da asma (Figura 2).

Concentrações séricas excessivas podem ser resultantes de erro do sistema de saúde, erro do paciente ou consequiência de interações com doenças (insuficiência cardíaca, hepática, febre) ou drogas. Sessler avaliou cinco mil quinhentos e cinqüenta e sete (5557) medidas de teofilinemia no pronto-socorro. Dez por cento apresentava-se acima de $20 \mu \mathrm{g} / \mathrm{ml}$, com $2,8 \%$ acima de $30 \mu \mathrm{g} / \mathrm{ml}$. Os fatores associados aos níveis elevados estão demonstrados na Tabela IV. Os efeitos colaterais mais comuns foram manifestações gastrointestinais, neurológicas (tremores e nervosismo), cardiovasculares e metabólicas. Convulsões ocorreram em $6 \%$ dos casos ${ }^{(6)}$.

O uso de teofilina de maneira tempo-dependente é melhor do que de maneira homeostática, ou seja, a concentração sérica constante, durante as vinte e quatro (24) horas, não é tão benéfica quanto em altos e baixos, nas horas adequadas. Martin et al. ${ }^{(7)}$ mostraram que níveis séricos constantes, em torno de 11 a $14 \mu \mathrm{g} / \mathrm{ml}$, não são tão eficazes como níveis menores durante o dia (7 a $8 \mathrm{mg} / \mathrm{ml})$ e maiores durante a noite, 16 a $18 \mu \mathrm{g} / \mathrm{ml}$. Na asma aguda, refratária ao tramento convencional e que pode levar à morte, a aminofilina deve ser usada em infusão lenta com monitorização constante e medida da concentração sérica.

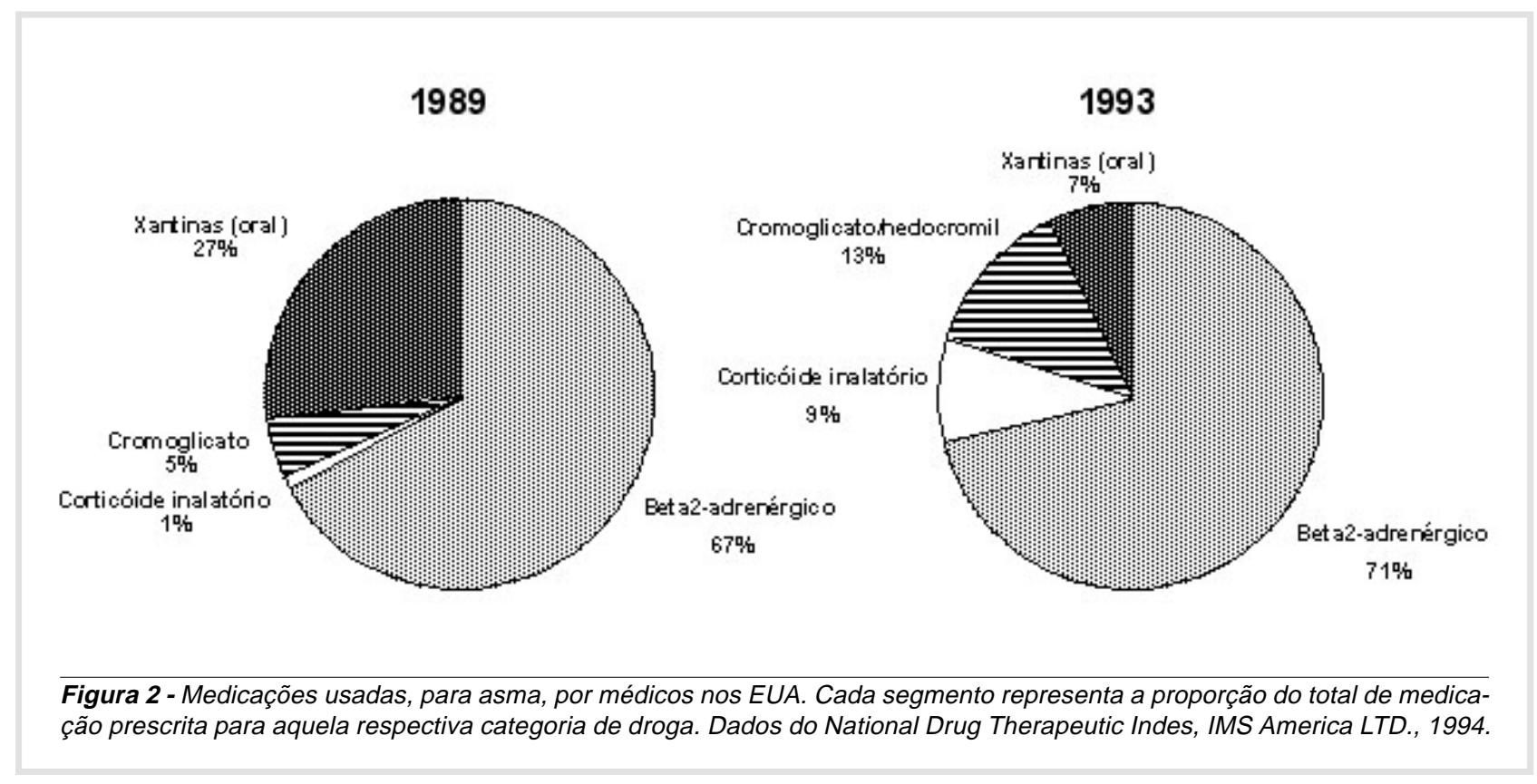




\begin{tabular}{lc}
$\begin{array}{l}\text { Tabela IV - Fatores associados à intoxicação por teofilina } \\
\text { em 116 casos }\end{array}$ & $\begin{array}{c}\text { Porcentagem } \\
\text { dos casos }\end{array}$ \\
\hline Fatores associados & 29 \\
\hline Erro do paciente & 17 \\
- Tomou dose extra para alívio dos sintomas & 8 \\
- Recebeu dose extra dos pais ou responsável & 3 \\
- Tomou a dose ou medicação incorreta & 1 \\
- Ingestão acidental por uma criança & 21 \\
Erro médico ou hospitalar & 16 \\
- Dose excessiva foi prescrita & 4 \\
- Duas receitas contendo teofilina & 1 \\
- Medicação identificada incorretamente & 20 \\
Defeito do metabolismo de teofilina & 14 \\
- Insuficiência cardíaca congestiva & 6 \\
- Doença hepática & 5 \\
Interação medicamentosa & 2,5 \\
- Eritromicina & 2,5 \\
- Cimetidina & 3 \\
Infecção por vírus & 10 \\
Tentativa de auto-intoxicação & 26 \\
Causa desconhecida &
\end{tabular}

Adaptado de Sessler (6). Em alguns casos, mais de um fator esteve associado.

\subsection{Broncodilatadores - Anticolinérgicos}

São antagonistas da acetilcolina, específicos para o receptor muscarínico e semelhantes à atropina. Portanto, aliviam a broncoconstricção mediada pelo sistema nervoso autônomo colinérgico. Apenas depois da introdução do brometo de ipratrópio, essa classe de drogas teve algum papel no tratamento da asma. $\mathrm{O}$ brometo de ipratrópio tem mínima absorção sistêmica, quando administrado por via inalatória, o que permite seu uso. Efeitos colaterais incluem secura da orofaringe, gosto desagradável após inalação, tosse, nervosismo e irritação pelo aerossol. O uso clínico de tais agentes, na asma crônica, se limita a substituir os agonistas $\beta_{2}$-adrenérgicos, quando o paciente não pode fazer uso destes e nem da teofilina, geralmente, por causa de efeitos colaterais. $\mathrm{Na}$ asma aguda, os estudos clínicos têm sido contraditórios. Enquanto alguns descrevem os efeitos broncodilatadores do ipratrópio, outros relatam falta de benefícios adicionais ao $\beta$-agonista.

\subsection{Corticoesteróides}

Os corticoesteróides (CS) reduzem a reatividade brônquica e recuperam a integridade das vias áereas. Entretanto, o mecanismo de ação que leva a esses efeitos ainda não foi completamente esclarecido. As moléculas entram na célula por difusão passiva, através da membrana. No citoplasma, ligam-se a receptores específicos para os glucocorticóides. A translocação para o núcleo e a ligação ao DNA são os próximos passos para os CS exercerem seus efeitos. Essas etapas são controladas por mediadores chamados fatores de transcripção (Figura 3).

A eficácia clínica é, em grande parte, decorrente dos efeitos inibitórios sobre o recrutamento de leucócitos para as vias aéreas. Quase todas as células que participam da fisiopatologia da asma, incluindo linfócitos, eosinófilos, neutrófilos, macrófagos, monócitos, mastócitos e basófilos, são susceptíveis à inibição pelos CS. A administração terapêutica desses fármacos proporciona redução dos parâmetros inflamatórios no lavado broncoalveolar, escarro e tecidos, concomitantemente à redução da hiperreatividade brônquica. Efeitos positivos na reatividade brônquica foram observados tão cedo quanto após três (3) semanas de tratamento com CS inalatórios. Infelizmente, a interrupção do tratamento resulta no retorno dos sintomas dentro de semanas a meses, após a interrupção ${ }^{(8)}$. Portanto, os CS inalatórios inibem os mecanismos subjacentes da asma e causam remissão dos sintomas, no entanto, sem curar a doença.

Os CS inalatórios para uso em asma são: beclometasona, flunisolida, triancinolona, budesonida e fluticasona. A vantagem dessas drogas reside na proporção da droga inalada que atinge a célula alvo, comparada à proporção que atinge a circulação sistêmica. A relação entre potência tópica/sistêmica é 0,1 para beclometasona; 0,05 para flunisolida e triancinolona; 1,0 para budesonida; e (ainda maior) 25,0 para a fluticasona. Outra característica desejável para tais corticóides é o rápido metabolismo e eliminação da porção que atinge a circulação sistêmica. Após inalação, 80-90\% da dose se deposita na boca e orofaringe e é deglutida. A porção fica, então, disponível para absorção, pelo trato gastrointestinal. A fluticasona e a budesonida são sujeitas a grande depuração, na 


\section{Receptores de glucocorticóides}

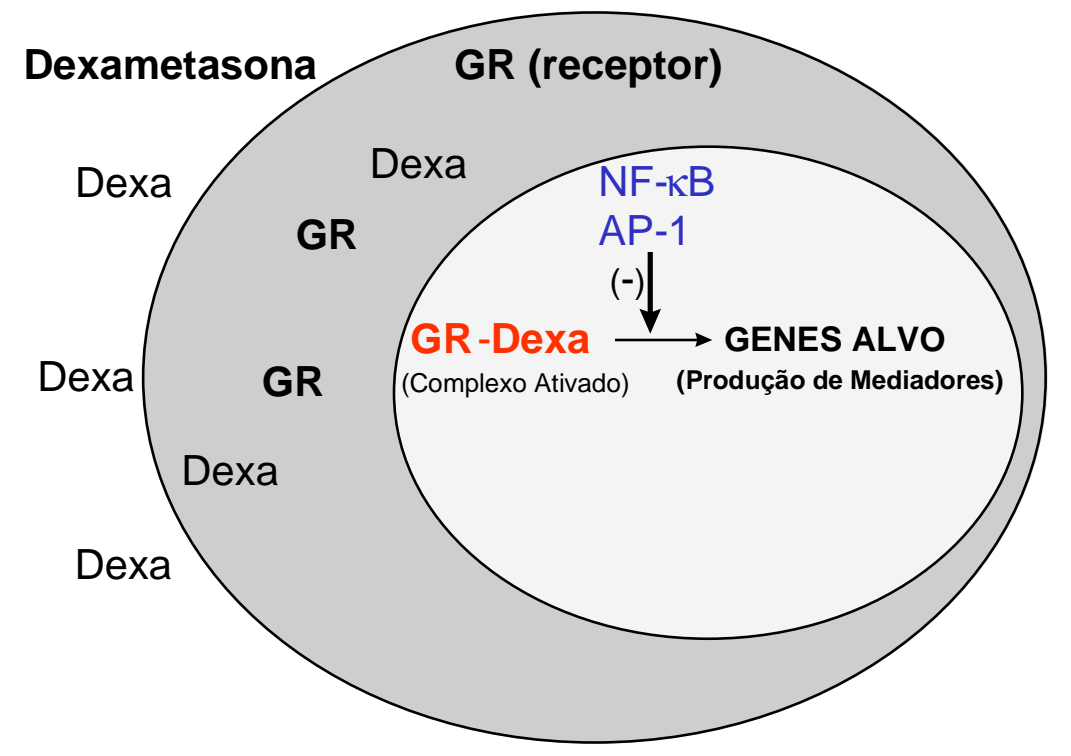

Figura 3 - Interações entre glucocorticóides e receptores.

primeira passagem pelo sistema porto-hepático, restando, portanto, menos para efeitos sistêmicos. Os efeitos sistêmicos são também influenciados pelo método de inalação empregado. Desde a escolha entre pó ou spray até a técnica correta de uso, muitos fatores influenciam a relação entre efeito tópico e sistêmico.

Os supostos efeitos colaterais dos CS inalatórios são supressão adrenal, desmineralização óssea, alterações do metabolismo dos carboidratos e redução do crescimento linear de crianças. Os dados disponíveis sugerem que doses menores de $400 \mu \mathrm{g} / \mathrm{dia}$, em crianças, e de $800 \mu \mathrm{g} / \mathrm{dia}$, em adultos, são consideradas seguras ou de pouco risco para a supressão do eixo hipotalâmico-hipofisário-adrenal. Os efeitos sobre mineralização óssea e metabolismo dos carboidratos são considerados pouco importantes do ponto de vista clínico, enquanto o crescimento peripuberdade é mais vulnerável aos CS inalatórios. Portanto, doses mínimas devem ser usadas em jovens. Efeitos locais dependem do método de inalação usado, dose e freqüência da administração. O mais comum é a disfonia (1/3 dos pacientes) que, como a candidíase, pode ser facilmente tratada. Por outro lado, efeitos colaterais dos CS sistêmicos são reconhecidamente problemáticos, na clínica pneumológica, e incluem: fraturas por osteoporose, catarata, ganho de peso, hipertensão arterial sistêmica, miopatia, intolerância à glicose, hematomas, insuficiência adrenal, disfunções imunológicas e várias alterações do humor e comportamento.

Os CS inalatórios são, atualmente, a primeira linha no tratamento de pacientes que precisam de broncodilatador quase diariamente. A dose a ser usada no início do tratamento ainda não está definida. Dois esquemas têm sido propostos: iniciar com dose baixa e aumentar ou iniciar com dose elevada e diminuir. Enquanto novos estudos são esperados para definir a melhor abordagem, doses elevadas devem ser reservadas para pacientes com asma mais grave. Em termos de freqüência, a administração em quatro (4) vezes ao dia pode ser reservada aos pacientes com asma mais grave, porque, com apenas duas (2) tomadas ao dia, a maior parte dos pacientes mostra resultados satisfatórios. Alguns estudos recentes, envolvendo cronoterapia com CS, adicionaram informações importantes nesse assunto.

Para pacientes com asma que piora à noite, a farmacoterapia deve intensificar seus efeitos nas horas de sono. Mas, mesmo no tratamento do asmático sem piora noturna, deve-se procurar o melhor momento para a administração das drogas a fim de se obter a melhor 
eficácia com o mínimo de efeitos colaterais. Num estudo de Pincus et al. ${ }^{(9)}$ um grupo foi tratado com dose única, diária, de triancinolona $800 \mu \mathrm{g}$ às 15:00 h e comparado a um outro grupo, que recebia $200 \mu$ g, quatro (4) vezes ao dia. A dose, administrada às 15:00 h, proporcionou resultados semelhantes aos da dose dividida em quatro (4) vezes, no que se refere à necessidade de broncodilatadores, valores de VEF1 e pico de fluxo da manhã e da noite. Além disso, o grupo tratado às 15:00 $\mathrm{h}$ não apresentou maior supressão adrenal ou outros efeitos colaterais. Quando quatro (4) vezes/dia foi comparada com dose total às 8:00 h ou 17:30 h, apenas o horário das 8:00 h foi significantemente inferior em termos de melhora clínico-funcional, após um mês de tratamento. Em conclusão, o horário da tarde é o melhor para a administração de CS inalatórios, o que já se havia mostrado para CS sistêmicos.

Todos os pacientes internados por crise aguda de asma necessitam CS sistêmicos, por vários dias. Entretanto, os pacientes que procuram o pronto-socorro ainda nos deixam na dúvida a respeito de quem necessita corticoterapia sistêmica como tratamento inicial. Os dados disponíveis evidenciam o benefício dos CS nessa situação e alguns dados indicam que a falta do uso de CS contribui para a morte por asma. Uma metaanálise, revendo mais de setecentos (700) artigos, identificou trinta (30) estudos de qualidade aceitável (aleatórios e controlados). Os autores concluíram que CS, administrados no pronto-socorro, reduzem o número de internações e o número de recidivas da crise (nos primeiros sete (7) a dez (10) dias). O tipo de administração, oral ou injetável, não faz diferença, desde que uma dose mínima de $30 \mathrm{mg}$ de prednisona (ou equivalente) seja administrada ${ }^{(10)}$. Novos estudos são necessários para a melhor definição da dose a ser usada no pronto-socorro.

\subsection{Antagonistas dos receptores de leucotrienos}

Esses agentes funcionam, bloqueando a interação dos leucotrienos (LTs) com o receptor cis-LT1, bloqueando, assim, a resposta do órgão-alvo aos LTs. A evidência para o papel dos cisteinil-LTs (LTC4, LTD4, e LTE4) na asma é a presença deles no pulmão humano, após broncoprovocação e a capacidade de induzir características da asma, como broncoespasmo, secreção de muco, transporte de muco diminuído, migração de eosinófilos para o pulmão e proliferação de músculo liso. Além disso, o desenvolvimento dos antagonistas de receptores somou dados sobre o papel importante desses mediadores na asma.

\subsubsection{Zafirlukast}

O tratamento com zafirlukast, um antagonista com alta afinidade pelo receptor, protege os asmáticos contra broncoprovocação por LTD4, broncoespasmo induzido por exercício, provocação alergênica e piora noturna da asma. A administração de zafirlukast também melhora os índices de função pulmonar. Uma metaanálise analisando cinco (5) estudos duplo-cego, controlados com placebo, indicou que a frequiência de crises de asma dos pacientes tratados com zafirlukast era a metade da observada em pacientes tratados com placebo ${ }^{(11)}$. Suissa et al. ${ }^{(12)}$ avaliaram a efetividade clínica e econômica de zafirlukast, estudando cento e quarenta e seis (146) pacientes com asma leve-para-moderada, em um estudo controlado, aleatório e duplo-cego. Como resultados, zafirlukast (20 mg, duas vezes ao dia) melhorou os seguintes parâmetros clínicos e econômicos: dias sem sintomas, dias sem necessidade de $\beta$-agonistas, dias ausentes do trabalho ou escola e visitas ao serviço de saúde. Os autores concluíram que zafirlukast é uma alternativa potencial aos CS inalatórios ${ }^{(12)}$. Porém, um estudo bem projetado, comparando um antagonista de receptor a um CS inalatório, ainda precisa ser executado.

\subsubsection{Pranlukast}

Pranlukast foi o primeiro antagonista de receptor de leucotrienos a ser comercializado. Estudos no Japão e depois na Europa e América do Norte mostraram que o pranlukast atenua a resposta a estímulos broncoconstrictores, inclusive exercício, aspirina, poeira de casa, metacolina e LTD4. Dois estudos em duplo-cego, paralelos, aleatórios, placebocontrolados selecionaram pacientes asmáticos adultos. $\mathrm{O}$ primeiro avaliou a segurança e a tolerabilidade de pranlukast, como também obteve dados preliminares sobre a eficácia. Durante a fase de tratamento, foram designados cento e trinta e cinco (135) pacientes, fortuitamente a um dos seguintes três grupos de tratamento: pranlukast $225 \mathrm{mg}(\mathrm{n}=46)$; pranlukast 337,5 $\mathrm{mg}(\mathrm{n}=45)$; ou placebo $(n=44)$. A droga foi bem tolerada e não foi observada nenhuma alteração hematológica ou nas variáveis bioquímicas. O VEF1 aumentou significativamente, dentro de uma hora depois da administração da primeira dose ( $225 \mathrm{ou} 337,5 \mathrm{mg}$ ), e este aumento foi mantido durante oito (8) horas. Durante as quatro (4) semanas de tratamento, os aumentos de VEF1 variaram de 210 a $340 \mathrm{ml}$. O pico de fluxo e os sintomas também melhoraram nas semanas 1 e $2^{(13)}$. 
O segundo estudo teve um protocolo semelhante com doses diferentes (337,5 e $450 \mathrm{mg}$ ), sendo que ambas causaram aumento do VEF1 a curto prazo. Os aumentos no VEF1 matinal variaram de 70 a $170 \mathrm{ml}$ com $337,5 \mathrm{mg}$ e 190 a $300 \mathrm{ml}$ com $450 \mathrm{mg}$, durante as quatro (4) semanas de tratamento. A melhora dos sintomas foi significativa na quarta semana para os pacientes com $450 \mathrm{mg}$. Nenhuma reação adversa grave ou inesperada foi atribuída ao tratamento ${ }^{(14)}$. Os resultados obtidos por esses estudos confirmaram dados prévios, embora estudos em execução definirão melhor o papel do pranlukast no tratamento da asma.

\subsubsection{Montelukast}

Montelukast (MK-0476) é um dos mais potentes antagonistas. Um estudo com diversas doses, aleatório, cruzado e comparado com placebo foi realizado para avaliar a tolerabilidade e eficácia clínica do montelukast, em pacientes com asma crônica (recebendo e não recebendo CS inalatórios). Vinte e nove (29) asmáticos receberam montelukast, $200 \mathrm{mg}$, três vezes por dia, durante dez (10) dias. Um total de onze (11) pacientes relatou vinte (20) efeitos colaterais, enquanto tomavam montelukast; porém, foram vistos números semelhantes quando o placebo foi administrado. Dois pacientes abandonaram o estudo por causa de eventos adversos: infecção respiratória e erupção cutânea. Essas complicações não foram consideradas como relacionadas à droga em teste. Dois casos de anormalidades laboratoriais foram descritas: subida passageira e moderada da bilirrubina e, em outro paciente, da ALT. Por outro lado, montelukast proporcionou melhor VEF1 nos dias um (1) e onze (11) do tratamento, diminuição dos sintomas diurnos e do uso de $\beta$-agonista. O estudo também demonstrou que os benefícios clínicos, observados em pacientes tomando montelukast, aconteceram independentemente do uso concomitante de CS inalatório ${ }^{(15)}$.

\subsection{Inibidores de síntese de leucotrienos}

Uma abordagem também promissora para o tratamento de asma é diminuir a formação dos leucotrienos. Os cisteinil-LTs são derivados do metabolismo do ácido aracdônico pela 5-lipoxigenase (5-LO). Várias drogas que inibem a ação da 5-LO estão em desenvolvimento e testes, por exemplo ZD-2138 e ABT761. O zileuton está disponível para o uso clínico e é o inibidor da 5-LO mais estudado, incluído em vários trabalhos clínicos. Outra abordagem visando, inibir a produção de LTs, é o bloqueio da 5-lypoxygenase-activating protein (FLAP), um cofactor residente na membrana nuclear, que apresenta o aracdonato para a 5-LO. Nessa classe de drogas, encontramos em desenvolvimento o MK-0591, LADRE x 1005 e MK-886.

\subsubsection{Zileuton}

Em estudos clínicos, o tratamento com zileuton proporcionou melhora da função pulmonar, redução dos sintomas, redução do uso de $\beta$-agonistas e das exacerbações de asma. Israel et al. ${ }^{(16)}$ estudaram o efeito de três (3) meses de tratamento com 400 e $600 \mathrm{mg} / \mathrm{d}$ de zileuton, em asma moderada. Apenas $6 \%$ dos cento e trinta e dois (132) pacientes que receberam a dose mais alta apresentaram crise de asma, contra $16 \%$ dos cento e trinta e cinco (135) pacientes que receberam placebo. Além disso, o VEF1 e a qualidade de vida melhoraram no grupo recebendo $600 \mathrm{mg}$. Elevações em testes de função hepática foram uma preocupação importante no tratamento com zileuton ${ }^{(16)}$. Outro estudo, para avaliar a eficácia a longo prazo e segurança do zileuton, mostrou, novamente, broncodilatação aguda, duas (2) a cinco (5) horas depois da dose inicial (400 ou $600 \mathrm{mg}$ ). No $36^{\circ}$ dia, o VEF1 melhorou 16\% em pacientes tratados com $600 \mathrm{mg}$. As mudanças de VEF1 para pacientes tratados com $400 \mathrm{mg}$ não foram significantes ${ }^{(17)}$.

\subsection{Uso clínico dos antileucotrienos}

Da informação atualmente disponível, parece que os antileucotrienos melhoram a função pulmonar e diminuem os sintomas, a freqüência das crises e a necessidade de broncodilatadores. A maioria dos estudos selecionou asma leve ou moderada, mas essas drogas podem funcionar melhor na asma moderada-para-grave. Embora tenha sido sugerido que os antileucotrienos sejam uma alternativa para substituir os CS inalatórios, incluindo pacientes que não conseguem usar medicação por via inalatória, não há prova de que isto é correto. A experiência clínica, em maior escala, poderá estabelecer um papel mais específico para essas drogas na terapia de asma. É importante ressaltar que esses agentes podem ser a primeira linha para o tratamento de algum subtipo de asma. É o caso da asma induzida por aspirina (AIA). Pacientes com AIA apresentam boa resposta terapêutica aos antileucotrienos (antagonistas de receptores ou zileuton). 
VIANNA EO. Bronchial asthma: today and tomorrow. Medicina, Ribeirão Preto, 31: 229-240, apr./june 1998.

ABSTRACT: Asthma is characterized by reversible obstruction, inflammation, and hyperreactivity of the airways. The diagnosis is based on clinical information and pulmonary function tests. Eosinophils are a main feature of the asthma pathophysiology. They produce bronchoconstrictor, chemotactic, and vasoactive products that lead to hyperreactivity. Also, they damage surrounding tissue, by releasing their cytotoxic granule content.

The recommendations for the treatment of asthma were organized around four components of effective asthma management: use of objective measures of lung function to assess the severity of asthma and to monitor the course of therapy; environmental control measures to avoid or eliminate factors that precipitate asthma symptoms or exacerbations; comprehensive pharmacologic therapy for long-term management designed to reverse and prevent the airway inflammation characteristic of asthma as well as pharmacologic therapy to manage asthma exacerbations; and, patient education that foster a partnership among the patient, family, and clinicians.

The $\beta_{2}$-adrenergic agonists are the most commonly used class of drugs for the treatment of asthma. Using this drug on an as-needed basis is now more frequently accepted and recommended. In acute asthma, a $\beta_{2}$-adrenergic agonist is still the medication of choice. Long-acting, salmeterol and formoterol, administered only twice daily, can decrease symptoms of asthma during day and nighttime. Theophylline, whose use has been limited by the potential for serious toxicity, may regain an important position in the asthma treatment with the development of the knowledge about its antiinflammatory actions. Dosing theophylline on a time-related basis also improves the risk/benefit ratio and makes theophylline a useful drug for nocturnal asthma. Ipratropium bromide, an anticholinergic drug, still awaits a defined role in the treatment of asthma. Corticosteroids, including inhaled forms, have measurable effects on symptoms, lung function, bronchial responsiveness, and inflammation associated with asthma. Side-effects of chronic use limit systemic administration, but not inhaled administration. Newer preparations, like budesonide, flunisolide, and fluticasone decrease the incidence of possible side-effects related to inhaled steroids by having better ratio of topical to systemic potency.

Newly released medications include anti-leukotrienes (LTs) agents which function either by blocking the interaction of LTs with receptors (receptor antagonists) or by inhibiting leukotriene synthesis (synthesis inhibitors). Representatives of the antagonists discussed here are zafirlukast, pranlukast, and montelukast. Pranlukast, the first leukotriene receptor antagonist to be marketed, improves lung fuction and symptons when $450 \mathrm{mg}$ b.i.d. is used. Zileuton, a leukotriene synthesis inhibitor, has been shown to improve lung fuction, reduce symptoms, reduce use $\beta$-agonists and asthma exacerbations. These positive effects are dose dependent and liver function abnormalities seem to be a relevant issue during zileuton use in some patients.

UNITERMS: Asthma. Bronchodilator Agents.

\section{REFERÊNCIAS BIBLIOGRÁFICAS}

1 - THE BRITISH GUIDELINES ON ASTHMA MANAGEMENT 1995 Review and Position Statement. Thorax 52, 1997. Suppl. 1.

2 - VENGE P. Eosinophil activity in bronchial asthma. Allergy Proc 15: 139-141, 1994.

3 - VIANNA EO \& GARCIA-LEME J. Allergen-induced airway inflammation in rats: role of insulin. Am $\mathbf{J}$ Respir Crit Care Med 151: 809-814, 1995

4 - NELSON HS. Beta-adrenergic bronchodilators. N Engl J Med 333: 499-506, 1995.

5 - DRAZEN JM et al. Comparison of regularly scheduled with as-needed use of albuterol in mild asthma. N Engl J Med 335: 841-847, 1996.
6 - SESSLER CN. Theophylline toxicity: clinical features of 116 consecutives cases. Am J Med 88: 567-576, 1990.

7 - MARTIN RJ. Circadian variations in theophylline concentrations and the treatment of nocturnal asthma. Am Rev Respir Dis 139: 475-478, 1989.

8 - HAAHTELA T et al. Effects of reducing or discontinuing inhaled budesonide in patients with mild asthma. $\mathbf{N}$ Engl $\mathbf{J}$ Med 331: 700-705, 1994.

9 - PINCUS DJ et al. Chronotherapy of asthma with inhaled steroids: the effects of dosage timing on drug efficacy. J Allergy Clin Immunol 95: 1172-1178, 1995.

10 - ROWE BH, KELLER JL, OXMAN AD. Effectiveness of steroid therapy in acute exacerbations of asthma: a metaanalysis. Am J Emerg Med 10: 301-310, 1992. 
11 - BARNES NC et al. Reduction of exacerbation of asthma in multinational clinical trials with zafirlukast. Am J Respir Crit Care Med 153: A802, 1996.

12 - SUISSA $S$ et al. Effectiveness of the leukotriene receptor antagonist zafirlukast for mild-to-moderate asthma. A randomized, double-blind, placebo-controlled trial. Ann Intern Med 126: 177-183, 1997.

13 - BARNES NC \& PUJET J-C. Pranlukast, a novel leukotriene receptor antagonist: results of the first European, placebo-controlled, multicentre clinical study in asthma. Thorax (In Press).

14 - GROSSMAN J et al. Results of the first double-blind, placebo controlled, multicenter clinical study in asthma with pranlukast, a novel leukotriene receptor antagonist. J Asthma (In Press).
15 - REISS TF et al. Effects of montelukast, a new potent cysteinyl leukotriene (LTD4) receptor antagonist, in patients with chronic asthma. J Allergy Clin Immunol 98: 528-534, 1996.

16 - ISRAEL E et al. Effect of treatment with Zileuton, a 5-lipoxygenase inhibitor, in patients with asthma. A randomized controlled trial. JAMA 275: 931-936, 1996.

17 - LIU MC et al. Acute and chronic effects of a 5-lipoxygenase inhibitor in asthma: a 6-month randomized multicenter trial. J Allergy Clin Immunol 98: 859-871, 1996.

Recebido para publicação em 13/05/98

Aprovado para publicação em 10/06/98 